\title{
Discussion on the Government Procurement in Colleges and Universities under the New Situation
}

Chao Luo

\begin{abstract}
State-Owned Assets Management Office of Neijiang Normal University, Neijiang, 641100, China
\end{abstract} 53188015@qq.com

Keywords: Colleges and Universities; Government procurement; Current situation; Measures

Abstract. Government procurement is one of the key points of current university work. Doing a good job in government procurement legally and compliantly is not only an external policy requirement, but also the internal needs of the use efficiency of financial funds in colleges and universities and the control of purchasing risk. At present, there are still many problems such as insufficient understanding, insufficient strength and ineffective implementation of government procurement in colleges and universities. We need to grasp the key points of government procurement in colleges and universities, recognize the new situation faced by government procurement in colleges and universities, conscientiously implement the existing legal system of government procurement, focus on strengthening post supervision of the government procurement in colleges and universities, and focus on strengthening the construction of government procurement institutions in colleges and universities, so as to make the government procurement work smoothly and healthily develop in colleges and universities.

\section{新形势下高校政府采购工作探讨}

\author{
罗超 \\ 内江师范学院国有资产管理处，内江 中国，641100 \\ 53188015@qq.com
}

摘要：政府采购做为当前高校工作的重点之一，合法、合规地做好政府采购工作不仅是外部的政策要求，同时也是提高 高校财政资金使用效益、控制采购风险的内在需要。目前我国高校政府采购工作还存在认识不够、力量不足以及落实不力等 问题，还需要切实包握住高校政府采购的重点，认清高校政府采购工作面临的新形势，通过认真贯彻落实现有的政府采购法 律制度、着力加强高校政府采购事中事后监管以及着力加强高校政府采购机构队伍建设等，从而使政府采购工作在高校得以 顺利推进和健康发展。

关键词: 高校; 政府采购; 现状; 措施

\section{1 前言}

《政府采购货物和服务招标投标管理办法》（财政部令第 87 号）于 2017 年 10 月 1 日正式实施，进一步规 范政府采购当事人的采购行为, 加强了对政府采购货物和服务招标投标活动的监督管理, 维护了国家利益、 社会公共利益和政府采购招标投标活动当事人的合法权益。随着国家财政对高等教育的投入逐步增大，高 校每年资金总量也越来越大，随之高校政府采购的任务也越来越重。随着我国政府采购的深入发展和不断 完善，高校越来越注重政府采购的规范执行，以更好地控制采购风险并保障学校财政性资金的安全和使用 效益。 


\section{2 高校政府采购工作的现状}

\section{1 政府采购认识不够}

虽然我国实行政府采购工作已经有很长一段时间了, 但是大家对其认识仍然不够, 没有真正认识到其严肃 性和重要性。高校严格执行政府采购也是最近几年的事情, 由于大家对其严格性和规范性还不适应, 经常 由于没有合理规划好时间而导致所需物品或服务不能及时到位。所以目前还有很大一部分人认为, 政府采 购耗时长、成本高, 不能满足高校教学科研的个性化需求, 抵触情绪较为严重。

\section{2 政府采购力量不足}

目前, 就高校政府采购力量的具体情况来看, 其力量明显不足。首先, 大多数高校没有独立设置招投标中 心, 大多数高校都将招投标中心挂靠在学校国有资产管理处。甚至有些规模较小的高校连国有资产管理处 都未单独设置, 更谈不上设置独立的招投标中心。由于采管未分离, 这样极容易造成权责不清。其次, 虽 然部分高校独立设置了招投标中心，但是却缺乏相应的专业技术人才。大多数招投标中心的工作人员都是 由非专业人员组成, 缺乏必要的专业知识。仅仅具备简单的服务功能, 根本谈不上对政府采购工作进行规 范管理、推陈出新。

\section{3 政府采购落实不力}

政府采购制度的实行在很大程度上规范了我国财政资金的使用, 也有效的预防了贪腐案件的发生。但是由 于其实行的时间并不太长, 还存在一定不足, 需要结合实际工作中的经验教训继续深化改革。由于高校涉 及到采购的种类繁多, 个性化需求较高。但是在目前现行政府采购制度下不能完全满足高校采购的实际需 要, 所以在高校政府采购中不同程度出现落实不力的情况, 有意拆分而规避政府采购的情形时有发生。

\section{3 高校政府采购工作的重点}

当前, 全国各项改革快速推进, 高等教育体制改革更是向纵深发展, 所以做为高校重点工作的政府采购改 革也要顺应这种变化, 就目前的实际情况来看, 高校政府采购工作应重点要把握好以下三方面关系。一是 把握好依法采购和加强服务意识的关系, 坚持 “法定职责必须为、法无授权不可为”。政府采购工作是一 项政策性非常强的工作, 必须严格按照国家相关法律法规执行。而高校政府采购涉及的种类繁多, 受供应 商数量、地域等诸多因素的影响, 实际工作中流标、废标等情形较多, 导致使用部门怨声载道。但是做为 高校政府采购管理部门而言, 只有尽量做好采购期间的服务、解释工作, 却不能因为图便捷、省事而违反 相关政府采购法律法规要求。二是把握好简政放权和加强监督管理的关系, 坚持 “抓大放小, 有所为有所 不为”。高校政府采购管理部门不但要按照政府采购相关规定, 对采购限额以上的采购项目委托政府采购 相关机构实施政府采购。同时, 由于高校政府采购限额以下的项目也较多, 也需要加强监督和管理。所以, 做为高校政府采购管理部门而言, 怎样合理高效的进行采购工作的关键在于根据各高校的实际, 科学设置 高校自己的各级采购权限。三是把握好基础工作和加强改革创新的关系, 要 “干好基础工作, 不断推陈出 新”。高校采购工作任务重且名目繁多, 但是人员力量稍显不足, 所以如何高效开展采购工作, 还需要不 断推陈出新，采取有效措施，不仅使得采购工作的合规合法，同时不断提高使用部门的满意度。

\section{4 高校政府采购工作面临的新形势}

随着我国经济社会发展方式转变, 政府采购工作所面临的形势也发生变化。对于高校政府采购工作而言, 
也需要根据我国经济的发展、社会的进步随之不断深入改进，以适应新形势的要求。

\section{1 经济发展方式转变对高校政府采购机制提出了新要求}

党的十八届五中全会提出创新、协调、绿色、开放、共享 “五大发展理念”。政府采购制度作为政府调控 经济、促进经济社会发展的重要政策工具, 须不断改革创新。这要求我们要积极发挥政府采购政策作用, 服务经济社会发展。高校政府采购作为高校工作的重点之一，关系到国家财政资金的有效利用，也关系到 高校教学、管理工作的顺畅运行。并且高校政府采购活动也是处于社会经济活动大潮中, 其必然要遵循社 会经济发展方式的变革要求。所以随着我国经济发展方式的转变, 同样也给高校政府采购活动带来了影响, 也对高校政府采购机制提出了新的要求。

\section{2 政府市场关系定位对高校政府采购管理提出了新要求}

党的十八届三中全会提出, 要处理好政府和市场的关系, 使市场在资源配置中起决定性作用。政府采购一 头连接政府, 一头连接市场, 我们要按照 “三公一诚信” 的基本原则, 更好发挥 “裁判员” 作用, 制定和 落实好比赛规则, 维护好公平公正的市场秩序。高校政府采购工作主要在于提出采购的具体需求, 介乎于 政府和市场之间, 当政府市场关系定位的改变, 必然会影响到高校政府采购活动的实施, 也对高校政府采 购活动提出了新的要求。

\section{3 依法治国法治理念对高校政府采购运行提出了新要求}

党的十八届四中全会提出, 建设中国特色社会主义法治体系。这使得增强政府采购法制在采购活动中的约 束力的要求更加明确。高校政府采购活动中同样要防止权力干预、权力滥用, 从而不断增强政府采购法制 的执行力和约束力; 同时也要管住政府采购中想乱伸的权力之手, 这就要求我们高校政府采购管理部门在 工作中发挥各方面的监督制约机制, 将内部监督、法定监督和社会监督相结合。国有资产管理部门作为高 校政府采购制度改革的主导者、操刀人, 要努力在构建规范透明、公平竞争、监督到位、严格问责的工作 机制方面下功夫，必须要使得我们高校的政府采购工作适应国家依法治国理念的新要求。

\section{4 全面深化改革任务对高校政府采购监督提出了新要求}

政府采购制度改革作为财政支出改革 “三驾马车” 之一, 已进入全面深化改革的新阶段，啃硬骨头、趟深 水区的事情会越来越多。同样, 高校政府采购也必然做出新的调整, 从职能、职责、方式等方面下深水。 这要求我们积极发挥政府采购监督合力, 要与监察、审计等监督部门建立联合监督工作机制; 同时发挥第 三方社会监督作用，用社会的力量促进高校政府采购良性发展。

\section{5 高校政府采购工作的对策}

\section{1 认真贯彻落实现有的政府采购法律制度}

严格贯彻落实国家政府采购相关法律法规是做好政府采购工作的前提，随着我国政府采购制度制度和体制 的不断完善, 已经形成了一套行之有效的管理体制, 可以在实际的政府采购活动中起到很好的规范和指导 作用。做为高校政府采购管理部门, 在实际工作中首先必须严格遵照国家相关法律法规要求, 其次还必须 根据自身的具体情况, 在不违反国家法律法规的前提下, 制定出适合本校的采购办法和管理制度, 从而不 断提高采购工作的合法性、规范性和效率性。

\section{2 着力加强高校政府采购事前事中事后监管}

采购自来就是党风廉政建设关注的重点, 我们的很多党员干部都因此而受到党纪国法的处罚, 特别是近年 
来高校政府采购领域也成了贪腐案件的高发地。所以加强高校政府采购的事前事中和事后的监管, 对规范 高校政府采购活动、防止贪腐案件的发生具有重要的意义。对高校政府采购的监督, 事前主要是对招标文 件制作是否合理、是否具有歧视性的监督, 具体检查商务、规格参数及评分细则等的制定; 事中主要是对 采购程序合法性的监督, 主要检查网络公告、标书售卖、开标程序、评标过程等情况是否合法合规; 事后 主要检查是否严格按照招标文件和投标文件的约定，对采购货物等进行严格的验收等。

\section{3 着力加强高校政府采购队伍建设}

政府采购工作既是一项政策性很强, 又是一项对技术性要求很高的工作。高校政府采购涉及到的种类繁多, 要求我们的高校政府采购组织实施人员不仅要熟悉政府采购各类规章制度的要求, 同时需要掌握各类仪器 设备的参数设置要求或服务技术要求, 只有这样才能做好高校政府采购工作。所以必须通过多种形式和多 种渠道加强高校政府采购队伍建设, 首先要使其熟悉国家政府采购相关法律法规, 其次要使其熟悉高校科 研仪器设备、服务的具体需求。只有这样才能做到既程序上合法合规、实际采购物品或服务能满足高校使 用需要。

\section{6 结语}

当前政府采购在高校采购工作中的比例和重要性日益显著，对高校来说，合法、合规地做好政府采购工作 不仅是外部的政策要求，同时也是提高高校财政资金使用效益、控制采购风险的内在需要。在政府采购工 作实践中, 高校采购部门需要明确政府采购的实施主体, 准确理解并正确选择政府采购方式, 规范执行政 府采购相关程序，并能切实推进采购信息的公开，从而使政府采购工作在高校得以顺利推进和健康发展。

\section{参考文献:}

［1］田璐，王杰，梁勇等．国外政府采购政策对我国高校政府采购的启示 $[J]$ ．实验技术与管理，2014，(6)：252-255.

[2] 耿强，孙勇. 公共财政视角下的高校政府采购市场监管机制探析 [J]. 实验技术与管理，2016，33(5)：257-260.

[3] 师秀清．高校政府采购网上竞价管理系统的实践与思考 [J]．实验室研究与探索，2011，30（3）：185-187.

[4] 高虹，刘玉晗，陆萍等．高校政府采购内部监督机制存在的问题及对策 $[J]$ ．实验技术与管理，2013，30（3）： 209-213.

[5］耿强，赵静．高校政府采购规范化管理研究与探索 [J]．实验室研究与探索，2013，32（1）：184-187.

[6] 王慧．高校政府采购工作的认识与思考 [J]．实验技术与管理，2013，30（6）：208-210.

[7］沈岗，陈洪婕，寿欣等．新政府采购法对高校政府采购的影响 [J]．商业会计，2015，（21）：95-97．

\section{References}

[1] L.Tian, J.Wang, Y.Liang, etc: The Enlightenment of Foreign Government Procurement Policy on Government Procurement in China's Universities[J], Experimental Technology and Management, 2014,(6):252-255.(In Chinese)

[2] Q.Geng and Y.Sun: An Analysis of the Supervision Mechanism of the Government Procurement Market in Colleges and Universities from the Perspective of Public Finance[J], Experimental Technology and Management, 2016,33(5):257-260.(In Chinese)

[3] X.Q.Shi: Practice and Thinking on the Online Bidding Management System of Government Procurement in Universities[J], Research and Exploration in Laboratory, 2011,30(3):185-187.(In Chinese)

[4] H.Gao, Y.H.Liu, P.Lu, etc: The Problems and Countermeasures of the Internal Supervision Mechanism of the Government Procurement in Colleges and Universities[J], Experimental Technology and Management, 2013,30(3):209-213.

[5] Q.Geng and J.Zhao: Research and Exploration on Standardized Management of Government Procurement in Colleges and Universities[J], Research and Exploration in Laboratory, 2013,32(1):184-187.(In Chinese)

[6] H.Wang: Understanding and Thinking of Government Procurement in Colleges and Universities[J], Experimental Technology and Management, 2013,30(6):208-210.(In Chinese) 
[7] L.Shen, H.J.Chen, X.Shou, etc: The Influence of the New Government Procurement Law on the Government Procurement in Colleges and Universities[J], Commercial Accounting, 2015,(21):95-97.(In Chinese) 